\title{
Is there any benefit to starting total parenteral nutrition early in very low birth weight infants? A systematic review
}

\author{
H. E. Moyses, M. J. Johnson, V. Cornelius and A. A. Leaf \\ NIHR Biomedical Research Unit (Nutrition, Diet and Lifestyle), Southampton Centre for Biomedical Research, \\ Southampton General Hospital, SO16 6YD, UK
}

Achieving adequate nutritional intakes in preterm infants is challenging, particularly in the first few weeks of life, and this may explain the poor growth often seen in this group ${ }^{(1)}$. The use of early total parenteral nutrition (TPN), initiated soon after birth, is one way of addressing this issue, though practice in this area is variable ${ }^{(2)}$. We carried out a systematic review to investigate the effect of early vs. late initiation of TPN on growth, morbidity and mortality in preterm infants. Electronic databases were searched to 31 st March 2011 for randomised controlled trials (RCTs) and observational studies (Obs). Nine studies were identified (1960 participants, 4 RCTs). Metaanalysis was performed where possible using Review Manager 5.1 (fixed effects model). RCTs and observational studies are reported separately. Studies were very heterogeneous, with variable methodologies and study time points. Growth and outcome measures were also inconsistent. This limited the potential for synthesis and meta-analysis. Key results in the table below compare early TPN with late.

\begin{tabular}{|c|c|c|c|}
\hline Nutritional effects & & Mean difference $(95 \% \mathrm{CI})$ & $\mathrm{p}$ value \\
\hline \multirow[t]{2}{*}{ Weight at discharge (g) } & $1 \mathrm{RCT}, \mathrm{n}=125$ & $31.0(-269.5,331.5)$ & 0.8 \\
\hline & 1 Obs, $n=440$ & $101.0(94.7,107.3)$ & $<0.001$ \\
\hline Time to regain birth weight (days) & 1 Obs, $\mathrm{n}=108$ & $-2.0(-3.5,-0.5)$ & 0.009 \\
\hline Weight at 36 weeks $(\mathrm{g})$ & 2 Obs, $\mathrm{n}=1111$ & $132.1(76.2,188.0)$ & $<0.001$ \\
\hline \multirow[t]{2}{*}{ Time to full enteral feeds (days) } & $1 \mathrm{RCT}, \mathrm{n}=40$ & $-2.2(-5.3,0.9)$ & 0.2 \\
\hline & $1 \mathrm{Obs}, \mathrm{n}=108$ & $-1.0(-5.0,3.0)$ & 0.6 \\
\hline Risks & & Risk ratio $(95 \% \mathrm{CI})$ & $\mathrm{p}$ value \\
\hline \multirow{2}{*}{ Necrotising enterocolitis (NEC) } & $1 \mathrm{RCT}, \mathrm{n}=105$ & $1.1(0.3,4.0)$ & 0.9 \\
\hline & 4 Obs, $n=1602$ & $1.5(1.0,2.2)$ & 0.06 \\
\hline \multirow{3}{*}{$\begin{array}{l}\text { Chronic lung disease/ } \\
\text { bronchopulmonary dysplasia }\end{array}$} & 3 RCTs, $n=283$ & $1.1(0.8,1.4)$ & 0.7 \\
\hline & 3 Obs, $n=584$ & $1.3(0.8,2.2)^{*}$ & 0.4 \\
\hline & 2 RCTs, $\mathrm{n}=154$ & $0.8(0.6,1.1)$ & 0.1 \\
\hline Sepsis/bacteraemia & 4 Obs, $n=1587$ & $0.8(0.7,0.9)$ & 0.008 \\
\hline \multirow{2}{*}{ Death } & 3 RCTs, $n=286$ & $0.9(0.6,1.4)$ & 0.5 \\
\hline & 3 Obs, $n=1150$ & $1.0(0.4,2.8)$ & 1.0 \\
\hline
\end{tabular}

Mean difference of $0=$ no difference between groups, Risk ratio of $1=$ no difference between groups.

*Random effects model used in preference to fixed effects due to significant heterogeneity.

Preliminary results here are limited by a relative paucity of evidence and the inconsistencies across studies described above. This highlights the disparate nature of measures reported for growth and nutritional outcomes in neonatal research, and demonstrates the need for defined core outcome measures in this area.

1. Embleton NE, Pang N \& Cooke RJ. Postnatal malnutrition and growth retardation: an inevitable consequence of current recommendations in preterm infants? Pediatrics. 2001 Feb;107(2):270-3.

2. Stewart JAD, Mason DG, Smith N, Protopapa K \& Mason M. A Mixed Bag: An enquiry into the care of hospital patients receiving parenteral nutrition. A report by the National Confidential Enquiry into Patient Outcome and Death (2010): National Confidential Enquiry into Patient Outcome and Death 2010 . 